Reynolds, F. \& Prior, S. (2003) 'A lifestyle coat-hanger': a phenomenological study of the meanings of artwork for women coping with chronic illness and disability. Disability and Rehabilitation, 25, (14), 785-794.

Purpose: The purpose of this phenomenological enquiry was to explore the meanings and functions of art for a group of women living with disabling chronic illness.

Participants were recruited on the basis that they considered artwork as central to their current well-being. Method: Thirty women were interviewed, and five submitted written narratives. Interpretative phenomenological analysis was carried out. Results: About half of the participants had taken up their preferred artistic occupation since the onset of illness. Participants described their artwork as contributing to their health and well-being in many diverse ways. Art filled occupational voids, distracted thoughts away from illness, promoted the experience of flow and spontaneity, enabled the expression of grief, maintained a positive identity, and extended social networks. Its value was conceptualised by one participant as a 'lifestyle coat-hanger' organising numerous further roles and activities that gave purpose to life. Art was more than cathartic. It offered a versatile means of overcoming the restrictions imposed by illness on self and lifestyle, in many cases creating a more enriched lifestyle than before. Conclusion: The findings may encourage professionals working in health and rehabilitation settings to assist clients in identifying meaningful, creative occupations that are feasible within the limits imposed by illness or injury. 


\section{'A lifestyle coat-hanger': a phenomenological study of the meanings of artwork for women coping with chronic illness and disability}

\section{Introduction}

Chronic disabling illness commonly disrupts roles and everyday occupations, leaving the person vulnerable to depression, loss of identity and dissatisfaction with life (1). For this study, a group of women were recruited who had taken up or expanded their artistic occupations in response to changing health, and who considered such occupations as central to their current well-being. The purpose of this phenomenological enquiry was to explore the meanings and functions of art for these women who were living in the context of a disabling chronic illness. To place a boundary around the focus of enquiry, the participants in this study all engaged in textile arts, including freestyle embroidery, tapestry, appliqué, quilting, and mixed media work. This form of artwork was selected because it is quite commonly practised by women, and yet is largely neglected in the occupational therapy and art therapy literature. Also, participants in a previous study showed through their detailed written narratives that they found it meaningful to interpret the role played by their artwork in coping with illness (2). It seemed likely at the outset that focusing on the common experience of working in fabrics and threads (to the exclusion of other art media) would assist the discovery of shared themes in the participants' accounts.

A wide body of research evidence suggests that chronic disabling illness often has deleterious effects on the person, not only through the physical discomfort and specific symptoms that it imposes, but through its wider effects on self, identity and lifestyle. For example, following on from stroke, individuals experience a split between the perceived body with its unfamiliar dysfunctions, and their familiar 
identities (3). Charmaz (1983) conceptualised the effects of chronic illness on identity in terms of a downward trajectory, as physical limitations increasingly interfere with valued roles and occupations at work and at home. During a chronic disabling illness, the person may feel increasingly isolated, depressed and helpless, experiencing a sense of dislocation from the familiar past self and painfully uncertain about the future. Bury (1982) referred to these encompassing effects of illness as a 'biographical disruption'.

Loss of meaningful occupation during chronic illness seems to have a particularly deleterious effect on well-being. For example, Jackson \& Quaal (1991) noted that 50$70 \%$ of people with multiple sclerosis become unemployed within a few years of diagnosis. Early retirement among people with other forms of chronic illness such as arthritis is also documented (7). Furthermore, financial difficulties, and loss of role within the family may occur as a result of losing one's job (8). Also, as self-esteem is fostered by the praise and recognition of others, it can become progressively eroded if the person is increasingly confined to the home and family.

Despite these very profound difficulties, some people do appear to regain an acceptable quality of life in the context of illness and loss of function. The restoration or discovery of meaningful occupation may have a vital role to play in influencing subjective well-being and a positive identity (9-12). Return to work during chronic illness may be psychologically beneficial, as noted among some men with HIV (13). Some disabled people decide to do voluntary work with disadvantaged people, campaign for the rights of disabled people, use their skills to raise money for charity, or make what they regard to be a meaningful contribution in other ways (e.g. 14-15). 
Nevertheless, for those who retire prematurely as a result of illness, an additional challenge arises of how to use extended leisure time productively (16). This may not be an easy task as a not only physical limitations but transport difficulties, and financial restrictions may restrict choice. Wikström, Isacsson \& Jacobsson (2001) found that people with rheumatoid arthritis reported a loss of about two thirds of their leisure activities. A poor quality lifestyle played out in a 'liminal' space (14) may also diminish well-being by increasing preoccupation with illness. People who manage to preserve favoured leisure pursuits and self-care activities during illness tend to have greater well-being $(1,16,18)$. To illustrate, a small qualitative study (19), explored the meanings of sea kayaking for three young people affected by spinal cord injury. Participants regarded this leisure pursuit as helping them to focus on and communicate an 'able' self, rather than being totally defined in terms of their disability. They valued the novel, stimulating experiences involved in this pursuit, and the opportunity to develop high level skills to cope with the challenges. The social and environmental aspects of this leisure pursuit also contributed to their well-being.

Volunteering has also been found to relieve depression and to increase self-efficacy for managing the pain of arthritis (20). Hence it is not only physical activity that has an effect on well-being, but occupations that fill the void of retirement and give the person a sense of making a worthwhile contribution, with a positive status in the community.

There is much to learn about the meanings that the continued practice of proficient physical, social and creative skills have for people living with frailty or chronic illness. Engagement in the creative arts is a strategy that appears to offer many psychological benefits for people living in the shadow of illness (21), being accessible 
to people with a wide range of physical impairments. However, the psychosocial benefits of creative endeavours have received relatively little research attention, outside of the art therapy literature. There are many ways in which the experience of creativity during leisure may provide an antidote to the stresses of illness, enhancing quality of life, and confirming an able identity. For example, creative products provide a visible record of achievement, increasing self-efficacy. Art therapists regard creative experiences as strengthening self-awareness and self-esteem, for example through enabling self-expression and 'voice' (22). Creative engagement, particularly in the visual arts, has been portrayed as offering a bridge between the conscious and unconscious (23), and therefore helpful for working through complex, deep-seated or 'unspeakable' emotions such as grief, because the creative process is directed by processes to which the person does not have full conscious access. This has particular relevance to people who may be mourning the loss of functioning or identity that physical illness or trauma has brought about (24).Emotionally charged feelings may be poured into artwork in a contained, oblique manner, without the anxiety that a direct confrontation would provoke (25).

Despite these various arguments and theoretical perspectives, few studies have explored participants' own interpretations of the personal meanings of artistic leisure occupation, and the meanings that it holds for their well-being and capacity to cope with illness. One exception was a study (26) interviewing community-dwelling older people taking part in an art exhibition about the meanings of their artwork for coping with ageing and increasing frailty. Participants described their artwork as maintaining their involvement in the wider community. It also contributed to their ongoing personal growth, through providing a productive focus to their lives, even in the face of physical limitations. 
A few artists living with chronic illness have provided autobiographical accounts that give insights into the meaning of art in their lives. For example, Longo-Muth took up art once after leaving her teaching career because of multiple sclerosis. She described her illness as encouraging her to re-prioritise, and to focus her limited energies on developing her creativity (27).

In a highly relevant previous study (2), written accounts were collected from 35 women with long-term health problems who reflected on the importance of textile artwork in their lives. More than half of the sample reported that they had immersed themselves in art after the onset of illness. For this particular group, art had not been a lifelong vocation. A common theme within the narratives was that a significant turning point in regaining quality of life during illness occurred when women discovered that art could be carried out with skill and satisfaction even within the confines imposed by illness. The women often referred to their artwork as restoring a familiar and satisfactory self-image, providing an able identity, and relieving negative feelings such as anxiety or depression. Furthermore, their creative occupations provided entry into new social networks, with the advantage that such relationships were based on mutual interests rather than 'caring' and 'illness'. Almost all participants regarded creative pursuits as a form of distraction or relaxation, helping to reduce feelings of depression or anxiety. Some of those who were facing a terminal illness portrayed their creative work as a legacy to others. A further study of the role of textile art in the lives of women experiencing depression (rather than physical illness) discovered certain overlapping themes (28). Contrary to initial expectation, relatively few participants in both studies described a lifelong interest in the arts. A large number had turned to artwork as a means of coping with a period of hospitalisation, or with early 
retirement on health grounds. Whilst the participants offered many insights into the functions that art played in the lives of people affected by chronic illness, the studies were limited in working with written narratives that were necessarily briefer than interview transcripts, and which presented information that could not be probed or clarified. In this current study, in-depth interviews with a new sample were carried out to further explore the meanings of art for women living in the context of chronic illness. Women's experiences were selected for study as many chronic illnesses such as multiple sclerosis and rheumatoid arthritis affect more women than men. Gender roles are distinctive, with disabled women regarding themselves as more subject to social discrimination (29), perhaps because cultural ideals about female appearance and roles are more prescriptive. The study was confined to the experiences of textile artists not because the form of art was considered as gender appropriate or particularly therapeutic, but simply to focus on a shared artistic medium.

The purpose of the study is to explore the meanings of art for women living in the context of chronic disabling illness such as rheumatoid arthritis and multiple sclerosis, from a phenomenological, 'insider' perspective. The findings may carry implications for enabling interventions by occupational therapists, nurses, and counsellors, when working with clients who have difficulties in regaining a satisfactory lifestyle following the onset of chronic illness and disability.

\section{Method:}

The research reported here was guided by the principles of interpretative phenomenological enquiry (IPA), as outlined by (30-31). This form of qualitative research is increasingly popular, particularly in the UK, for analysing interview data concerning experiences of health and illness (e.g. 32). The analytic approach is useful 
for uncovering the central, common themes in participants' accounts of their experiences, as well as for highlighting individual differences. The analytic method assumes that verbal accounts provide genuine insights into lived experiences, and that participants' stories are not simply self-presentational devices. It shares with American phenomenology the assumption that participants' thoughts, reflections and interpretations can be as much the subject matter of enquiry as their 'raw' sensory experiences (33). Clearly all interviews are the co-product of interviewer and interviewee, with both partners influencing the agenda and emphasis within the accounts (34). Nevertheless, 'realist' assumptions that the interview data reveal enduring cognitive and emotional responses, and convey credible insights into the person's lifestyle, were supported in this study by the abundant artwork on exhibition in the participants' homes.

Participants: Following ethical approval from the University ethics panel, thirty women with relapsing-remitting or progressive forms of MS were recruited to participate in the study. A further five preferred to provide lengthy written answers to the interview questions. Studies employing IPA often have much smaller samples (e.g. see reference 32), but given the diversity of health problems of the participants, it was considered advantageous to gather as wide a variety of personal experiences as possible. Invitations for study volunteers were displayed at local adult education centres, on relevant craft web-sites, and in a national UK textile art magazine. Women coping with long-term illness who regularly engaged in textile arts were requested to join the study. Thirty nine initially volunteered, but four did not reply after receiving the information sheet and consent form. Participants reported a range of chronic illnesses, including multiple sclerosis, post-polio syndrome, arthritis, severe respiratory problems, chronic fatigue syndrome and cancer. The age range was 29-72, with the 
majority aged between 48 and 65 . They resided in many areas of the UK. All were White. The majority were married, and had adult children living away from home. Three participants had school-aged children. The majority had professional qualifications, for example, in teaching, social work, physical therapy, nursing, and graphic design. In line with previous evidence about the impact of chronic illness, almost all had retired - three at the usual retirement age, but in other cases retirement had occurred on the grounds of ill health. Everyone described their illness as beginning more than two years previously confirming its chronic status. Almost all participants had taken at least one course in one of the textile arts (e.g. adult education classes, City \& Guilds courses), and many had exhibited their work, at least locally.

Procedure: The in-depth interviews in most cases lasted for about one and a half to two hours. Most were carried out in participants' homes (except for one participant who was interviewed in hospital at her own request, and for three who were interviewed by telephone because of distance). Open questions, shown to the interviewee in advance, were formulated to guide a focused conversation. The 'grand tour' opening question was simply 'tell me about yourself' in order to encourage the participant to create her own narrative. The interview explored the woman's experience of illness and disability, the process whereby her interest in textile arts had developed, and the part that artwork had played in promoting well-being, positive self-image, and coping with change.

Data analysis: Data analysis for this paper was carried out jointly with the second author, an occupational therapist with counselling qualifications, and experience in both mental health and physical health settings. The distinctive yet complementary professional backgrounds helped to ensure that the interpretation of themes was not simply a manifestation of an individual researchers' professional socialisation, and aided the transparency of the coding process. The second author did not have familiarity with the earlier study (2). This assisted the bracketing process, and the 
freshness with which the themes could be identified. The interviews were transcribed fully, and were read and re-read to sensitise the authors to major themes. Based on the guidelines for IPA (30-31), three long, rich interview transcripts were initially selected, provided by women living with different physical illnesses. The transcripts were initially coded by each researcher independently to draw up a provisional list of phenomenological themes, and to identify any the views and experiences shared among participants. Brief descriptive codes were annotated on each transcript, and after much immersion in the data, these were grouped into broader interpretative themes. The themes were checked and added to, during subsequent analysis of the remaining transcripts. Particular attention was given to the themes that the interviewees had validated at the time of interview, when their views had been summarised and reflected by the interviewer.

\section{Results:}

Artwork held a number of different meanings for participants, and these are summarised in Table 1.

Insert Table 1 here.

The various themes were arrayed along a dimension, with some relating more strongly to the experience of coping with the specifics of illness and losses (such as pain, and empty time), whilst others seemed to make a greater contribution to living a full and satisfactory life in the context of an enduring illness (such as expanding social networks and widening horizons). Artistic occupations clearly held many therapeutic benefits, addressing the dual tasks that people face when diagnosed with a chronic illness, namely to manage the limitations and discomfort of illness, and to build a 
'normal', satisfying life that breaks out of the confines imposed by illness (35). The themes will be further described and illustrated with quotations from the interviews.

\section{Distracting thoughts away from illness}

Particularly in the early stages of illness, for example around the time of initial diagnosis, hospitalisation or treatment, most participants reported being very preoccupied with anxiety about their health, and their future. Such worries were particularly vivid for women diagnosed with cancer, or other life-threatening conditions. Many sought refuge in an absorbing occupation at that time. In some cases, long-standing interests in textile art were drawn on, but others seemed almost by accident to encounter the value of textile art for distracting their thoughts away from illness. Even quite repetitive forms of stitching were effective for focusing attention, and for providing some relief from the otherwise constant worry about health. Textile art provided a means of coping with overwhelming emotions, not by denial, but by providing a positive alternative focus for attention.

A participant with multiple sclerosis explained how art helped to distract her thoughts away from her discomforting symptoms:

When you're working creatively, you're not thinking about things that hurt, or pains, or aching, spasms, or whatever, or your head spinning as you go dizzy, all the things you get, incontinence, the nasty things that happen (Sue)

\section{Expressing grief}

Strong feelings of loss, as well as worry, often preoccupied participants in the early stages of illness and disability. Artwork was felt by some to provide an avenue 
through which to express their complex feelings. However, almost every participant who poured her feelings of anger or sadness into her artwork did so without much awareness of the process at the time. Such participants mostly only recognised the cathartic nature of their early artwork considerably later in the adjustment process. For example, a participant who had gone through chemotherapy treatment for breast cancer described the grief that she had expressed in her artwork at that time:

When I look back now, I did the most gruesome, scary drawings...obviously that was how I was feeling inside I presume (Joyce)

The theme of symbolic transformation of feelings about illness through art is more fully developed in (36)

\section{Filling an occupational void}

For almost every participant in the study, poor health had led to retirement on health grounds, either directly because of mobility problems, pain and so on, or because illness had brought about a re-evaluation of priorities. Even those who felt that they had made a voluntary decision to retire encountered difficulties in using time productively, and those who felt their retirement was enforced faced an even greater sense of dislocation. Art provided a means to fill the occupational void with satisfying, creative activity, paving the way for a positive re-evaluation of lifestyle, and self-image. The various functions played by art were often inter-linked. For example, by filling time productively, participants no longer focused obsessively on illness. Some felt that not only had their mental health improved as a consequence, but that their physical health had also benefited. 
For example, the participant with multiple sclerosis (quoted previously) recounted the voids in her lifestyle that appeared as her functioning deteriorated, culminating in early retirement from work just as her daughters were leaving home. Immersion in textile art helped to fill these voids:

I was totally absorbed in my family, my job, really absorbed in it... We used to do an awful lot of walking, which I miss...so it's channelling this energy into something new.' (Sue)

\section{Increasing choice and control}

Illness is often experienced as taking away control and choice, placing burdens upon the person that are additional to symptoms and physical discomfort. Whilst participants generally acknowledged that they had limited direct control over their health (for example, in multiple sclerosis, or in cancer), they found solace and positive joy in the control that they could exercise over their creative products, and in the additional creative activities that they participated in, such as courses and exhibitions. This seemed to provide a psychological antidote to the helplessness and 'victim-hood' commonly induced by illness. One participant with a neurological illness explained: \{Art\} is a great thing for me to be able to do, because I get quite depressed not being able to do things, but ... it's something that I can do while I'm sitting here feeling lousy, it's a real achievement, it really perks me up. Yes, it is, very important. I mean that together with my sort of painting and drawing, that's what keeps me going, really (Lilith) 


\section{Increasing present-moment awareness}

Some women noted that since immersing themselves in creative occupation that they had developed more aesthetic awareness. This encouraged them to be appreciative of their surroundings, even in mundane situations, and increased their attention to colours and designs, even in everyday objects. As a consequence, they focused less often upon their ill-health. When not directly engaged in artwork, their thoughts often turned to the planning of designs for their next project, taking stimulus from the local surroundings. The development of present-moment awareness not only helped to distract thoughts away from illness or worries about the future, but sharpened perceptions and enriched the quality of everyday experience. A participant with metastatic breast cancer described with enthusiasm the pleasure she gained from being attentive to her surroundings:

I'm very observant...when I'm sitting on the beach, the pebbles aren't all the same colour. I'll think that bit of rusty chain against that grey stonework is an interesting colour (Christine)

\section{Enabling the experience of flow and spontaneity}

Every participant talked about the pleasure that she experienced in working creatively, whether in planning designs, or carrying out her artwork. Some of the pleasure was associated with being spontaneous, that is, enacting the plans and ideas that the woman had in mind for her artwork, and in making fresh decisions along the way. Such experiences of spontaneity may be interpreted as providing another antidote to the experience of chronic illness. Illness, for many participants, had made travel outside the home painful, effortful, or almost impossible. The contrasting experience of freedom that was gained from being able to pursue goals successfully in artwork was highly valued. A participant who used a wheelchair as a result of multiple 
sclerosis conveyed the sense of freedom that she gained through designing and machine stitching her artwork:

The spontaneity ..is what sees me through the bad times, because as it flows through me...there's no restrictions...it's endless, the only restriction is your imagination' (Sue)

Some participants seemed to describe an experience akin to 'flow' (37), which has been conceptualised as occurring when the person uses high level skills effectively to cope with meaningful challenges and to pursue clear goals. Flow is an experience akin to an adventure, and the satisfaction that is gained from successfully reaching goals and overcoming obstacles along the way, provides self-esteem. The engagement in flow should not only be considered in narrow terms as contributing to coping to illness. Whilst it provided another antidote to loss and limitation, it had a wider role in enabling a positive quality of life. Flow experiences were not common in the early stages when skills for textile art were being mastered. Some women described the initially rather tedious and repetitive practice of certain skills in order to master them. However, once equipped with more advanced techniques, the woman gained the power to reach a high standard, and enjoyed the sense of achievement gained. Most of the participants - even those with marked mobility problems - had attended at least one course in embroidery, or other form of textile art, which testifies to the satisfaction derived from learning and mastering skills.

\section{Revising priorities}

A further theme detected in many participants' accounts was that the discovery of art as a meaningful occupation in illness had encouraged the revision of priorities in their 
lives as a whole. This occurred on many levels. Some found that they needed to give less attention to pursuing the previously valued goals that were being threatened by illness, such as maintaining their careers. Instead, they gave themselves 'permission' to immerse themselves in creative occupations. It has been noticed in previous research that illness is sometimes experienced as a positive catalyst for lifestyle and identity change. This study indicates that for some participants, it was not illness per $s e$ that catalysed change, but the discovery that personal energy and commitment could be channelled into a meaningful creative occupation in the aftermath of illness. A participant who had given up a valued career in the health service after struggling with chronic fatigue syndrome for many months, described her strategies of resisting social pressures to take on too many responsibilities, once she had decided to reprioritise her activities:

I had actually had a responsible job before and I could still do it, my talent hasn't gone just because I'm not working any more ...I have to watch myself because I did all those things before, that I don't take on too many \{responsibilities\} because when you're at home people think you've got lots of time, you can do it, and because I don't look ill the majority of the time, people assume you're fine, they forget actually this person is ill. And then I shock them by appearing and looking dreadful. In the last four years, it's gradually built up so that my whole life now rotates around the textile arts $\{$ Lydia\}

With revised priorities, came new pleasures, skills, and future plans. Life seemed less circumscribed by illness, uncertainty and limitation. The possibility arose of further positive benefits, as described next. 


\section{Facilitating joy, humour and other positive emotions}

Illness is generally a joyless experience, and indeed many participants vividly described the pain and outright horror of their first encounters (for example with discovering a suspicious lump or with the chemotherapy that followed). The positive pleasures of artwork provided much relief from negative emotions, and perhaps signifying this relief, many narratives in which participants described discovering textile art were punctuated with humour and laughter (38). One participant taking morphine to control the chronic pain of severe rheumatoid arthritis described the powerful, positive experience that she gained through her work:

My biggest inspiration is nature. A lot of the sea, rocks and flowers and things. Often when we go to Aberdovey I sit on the beach and George walks the dogs and picks me up on the way back. So I get the chance to photograph and draw. I would say really that nature is my biggest inspiration for me personally. ...We had some poppies in the garden, the ones with the very shreddy petals and they were such wonderful colours and I thought what can I do to preserve these? So I actually ended up bonding them onto fabric and when I'd done that, it looked like a fire. So I then layered more fabric over and machine embroidered it and turned it into a forest fire ... I did some blackened trees on it. This thing was very sort of 'Wow, look at that!' because it was red and black. Everything else in the exhibition was beautiful but nothing that was remotely like that...because it was so different and bold (Shirley).

Further pleasure was derived from participating in courses, exhibitions, and the cameraderie of fellow needlework practitioners. Even trials and 'failures' - when newly tried techniques did not produce the results being aimed for - could provide 
relief from the stress of illness. Unlike illness, artistic failures could always be recuperated from, and in any case enriched daily life with learning opportunities.

\section{Restoring a positive self-image}

Illness has been represented as a potential master status (39) and indeed this seems to encapsulate how many participants first felt at the outset. Loss of career, difficulties in performing important roles such as being a 'good' mother to children, and awareness of an uncertain future, all tended to dismantle the familiar sense of self. For many participants, textile art was described as restoring self-esteem, through for example, personal satisfaction with artistic products, as well as the positive feedback that others provided. The woman's former sense of agency and capability were restored through her artwork, enabling some re-connection with valued aspects of her former self. Moreover, her artwork provided others with evidence of her ability, enabling relationships to be developed on that basis rather than being focused on her illness or physical limitations. This theme will be described in more detail next. One participant with a neurological problem said:

It's a horrible feeling that you can't achieve anything. Obviously I'm not able to work at the moment and I can do things like this \{hand-made cushion covers and bedspreads $\}$... things that are just for me. I find that really important. I think, because I just do it for myself, I don't do it for anybody else, and it's really important for me to do good things for myself, you know, to keep my self esteem up, to treat myself well. So, if I do something that makes my surroundings beautiful, that's really, really important to me. You know, I get a lot out of that (Lilith) 


\section{Building new social relationships}

It is well recognised that people with chronic illness cope better if they have good social support. It has also been observed that social networks tend to shrink in chronic illness (e.g. 40) The participants in this study described experiences counter to this trend. Almost all described meeting people through their artwork - whether neighbours who shared their interests, women attending local meetings of the Embroiderers' Guild, fellow students on courses, and people visiting textile art exhibitions. Moreover, these new relationships were based on mutual interests rather than issues connected with illness or caring. Whilst the friends and colleagues who were met in this way sometimes offered support with aspects of the illness or its effects (e.g. pushing a wheelchair around an exhibition), they also helped the woman to focus on shared interests rather than her illness, thereby improving her quality of life, and positive sense of self. A participant who had fulfilled a lifelong ambition by enrolling on a fine arts course following medical retirement after 38 years in the health service said:

I just love being with younger people, there's a group of about 30 on the foundation \{fine arts\} course, they're just absolutely lovely to be with, I just love it, I mean they're so daring with their art-work, they just do it, and I'm really enjoying being with them, and I've met other people along the way as well, and so it's been a good move really ... I feel I've 'come home' in a way, I can talk about things I want to talk about (Joyce)

\section{Contributing to others}

Linked with the previous theme, artwork was seen as maintaining well-being through enabling participants to make a contribution to others, whether through hand-made 
gifts, assistance with sewing projects, or fund-raising for charity. Some commented on how they reciprocated the help given by others with artistic gifts, and thereby maintained mutuality in their relationships. Positive satisfaction, self-efficacy and self-esteem were derived from the experience of contributing to the well-being of others.

I find doing the embroidery gives you a little bit of dignity because I feel I can give back because I don't want to keep taking from life. I want to give as well (Elaine, with multiple sclerosis)

\section{Widening horizons - embracing new activities and making future plans}

Illness creates uncertainty about the future, and can leave the person stranded in the 'empty present' (41). Many participants seemed to resist this effect, referring to their artwork as giving them a positive sense of future. Their plans for further art projects helped to increase their determination to cope with present ill-health and maximise recovery. Having an ongoing project seemed to some to almost 'guarantee' their survival. Future plans established hope. This future-orientation did not simply arise out of any long-standing or dispositional optimism as many participants described themselves as deeply uncertain or depressed about their futures at an earlier time in their illness. Immersion in artwork seemed to have provided a turning point in facing the future, through setting up projects with short-range and long-range goals. Such goals and prospects were very life-affirming and helped the woman to focus on the gains in her life, rather than the losses induced by illness. Positive growth and transformation had been made possible. In illustration, one participant in her late 60's who had rheumatoid arthritis, a mastectomy, and severe osteoporosis resulting in 
difficulties even leaving her house, described some of the activities that enriched her life:

It \{quality of life $\}$ is excellent, absolutely excellent. I could make a very good case for it being bleak, very bleak, but I have chosen to turn it around and in fact it's not bleak at all, it's just absolutely wonderful. I haven't really got the time to do all the wonderful things that I've got planned, all the things I've started, all the projects, all the books, all the things I've listed I might do. I've made it a very, very enjoyable life. ... about $90 \%$. I do read a lot, and I do like to think that I write a little bit, nothing very much in the way of being published, a few poems... but I read, I write, I sew, I do so many things really, yes...The list is endless really. I'm doing a very large mirror surround, with an angel at the top... I'm doing freestyle canvas work, a map of the UK.... I've put everything in it, bits of silk, beads, buttons, it's quite lovely actually, even though I say so myself (laughs) My latest thing is beadwork at the moment. I also belong to a bead-workers guild, I forgot to mention that, and a friend took me to Coventry in May for a big weekend bonanza. And when I was there I was asked to do an article for the bead workers guild journal (Bridget)

\section{A summary theme: Art as a lifestyle coat-hanger}

Many studies adopting IPA search for a central theme. The analysis showed that artistic involvement had many meanings for each participant, and clearly provided a versatile means of living with chronic illness, and maintaining well-being. One participant (with rheumatoid arthritis, hip replacement and recent experience of breast cancer) summarised the meaning that art had for her, using the metaphor of a 
'lifestyle coat-hanger' upon which many other activities could be hooked to fashion a 'normal', satisfying life. This seemed to provide a vivid label for the central theme:

Art blocks out sad thoughts or frightening thoughts and scary bits, you know, but it also moves you on. It got me going to exhibitions in London, impressionists and that sort of thing, absolutely wow, and you go home and you think I could do that, it's only brush strokes, and you go home and it looks like the dog's dinner (laughs) but it's brilliant just to try that. ... \{I was so proud I went up there on my own, it wasn't long after my radiotherapy had finished, and it was absolutely wonderful... it was a mix of inspiration and somewhere to go, all the lifestyle coathangers if you like, to hang your life on to (pause) and for me that was actually quite important. And I think it is illhealth or adverse things that make you look at creative things in a different light, they are absolutely essential. I think without it, it would have been harder to get back to the level of health that I've got to (Jane).

\section{Discussion}

In researching art-as-therapy, art therapists have illuminated a number of benefits of art for people living with chronic illness, particularly focusing on self-expression and catharsis. This study has illuminated a wide range of further meanings within the artwork experience when taken up as a leisure - rather than therapy - occupation. In some ways, artistic occupation helped participants to cope with the restrictions imposed by illness. But art also provided a means of positively enhancing the quality of life, for example through extending social networks and setting up future goals. 
The importance of having goals and hope for the future has been noted in previous studies of people with disabilities $(35,42)$.

Some of the psychosocial benefits described by participants may be particular to artwork (eg the means of expressing grief) but it is possible that many similar lifeaffirming experiences may be gained via quite different forms of personally valued activities and projects (e.g. gardening, volunteering). The pleasure of making a contribution to others, and filling occupational voids has for example been noted in a sample of volunteer workers with arthritis (20). To what extent any personally valued occupation - whether creative, social, or physical - has common life-enhancing elements needs further research. A reconstituted sense of self among people with disability has been presented as dependent upon maintaining hope for the future, regaining personal control, positive social support, and meaningful engagement with life, in a study of spirituality in disability and chronic illness (42). These overlapping themes provide some confidence in the experiences that have been identified as making a positive difference to quality of life and self-image in illness.

The in-depth interviews confirmed some of the insights already gained from a thematic analysis of written narratives (2). The previous study uncovered a number of therapeutic experiences within textile art such as the preservation or regaining of a satisfactory self-image, distraction from worry, positive enjoyment, maintaining and extending social networks, contributing to others, filling an occupational void through productive use of time and coping with an uncertain future. The current study offered some validation of the previously established findings and gathered more detailed insights about each one of these areas of experience. Furthermore, interviews provided new insights into the ways in which artistic occupation assisted the 
experience of grieving, flow, the revision of priorities, and the intensification of present-moment awareness. The former study was guided by a stress-coping framework (43), and therefore was confined to theorising about the relevance of artistic occupation specifically for managing chronic illness, and dealing with the threats and losses involved. This phenomenological enquiry has not only uncovered more detail about the meanings of art for women living with chronic illness, but suggests that coping with illness is only one aspect of concern to those affected. The other equally important task is to fashion a full and satisfying life, with integrity, selfesteem, positive relationships and so on. Art is not a simple uni-dimensional activity, but represents a 'lifestyle coat-hanger' upon which other life affirming activities, including educational courses, charity work and travel, can be hooked.

It is being increasingly recognised in the chronic illness and disability literature that some people engage in transformational coping and growth, as a result of illness. Progressive narratives (in which people describe positive outcomes from negative life events) and 'benefit-finding' have been noted among chronically ill people, even among those with deteriorating conditions such as those with multiple sclerosis (4445). This study provides further illumination of the process whereby illness may have positive consequences. People who are fortunate enough - whether by serendipity or planning - to discover a fulfilling occupation that enables self-expression, personal development and mutual social relationships, may understandably believe that illness has brought some gains into their lives.

Nevertheless, even with their immersion in artwork, the participants' lives were not without difficulties . Ongoing mobility problems, pain and anxiety about the future (e.g. the possibility of the return of cancer), continued to frustrate and sadden 
participants at least from time to time. Some women still felt unsure about their future roles (e.g. whether they would be able to return to a valued career if their condition improved) and were concerned about the social image that they presented to others. This finding corroborates certain previous observations that people can experience a complex mix of positive and negative responses to adverse life events (46), and that in illness, a normal biography can co-exist with the experience of biographical disruption (47).

Clearly the study has limitations. The participants tended to be drawn from a fairly narrow social class, being mostly professional, well qualified women. They may have had particular resources and skills enabling greater choice over daily occupations. They were White and therefore did not represent the full diversity of women in the UK coping with long-term health problems. Their particular cultural background may have been relevant to their approach to managing life with a long-term health problem, and this needs further enquiry. It remains unclear how personality and childhood experiences, as well as current social context, assisted the women in coping with illness and in choosing to focus on art in their daily lives. Also, participants were living with a wide range of different illnesses, and further enquiry is needed into whether art has distinctive meanings for women facing life-threatening, or particularly painful, conditions. None had profound impairments as can be seen following stroke or spinal cord injury.

Caution is also needed in interpreting the verbal accounts. As interviews are inevitably a co-production of interviewer and interviewee, it is possible that participants framed their answers in ways that they thought the interviewer 'wanted'. 
Nevertheless, some confidence is warranted that participants' views were not simply self-presentational devices, as the women showed portfolios of their artwork in their homes, and in one case, a local exhibition. Also the themes presented appeared in many participants' accounts, giving some confidence in certain shared aspects of the lived experience.

Further enquiry is recommended into the role of creative arts for people coping with long-term illness and also the health problems associated with ageing. It is important to examine whether any of the meanings of art located in this study are particular to textile art. The findings reveal women's resourcefulness in living with illness and regaining well-being through meaningful artistic occupations. Health professionals, including occupational therapists, counsellors, and nurses, might give more attention to the power of creative pursuits for rebuilding lives blighted by disabling illness, and for fostering the short-term and long-term goals that help individuals resist depression. Creative occupations may provide a sense of future, social contacts, and an enjoyable means of filling occupational voids. Although the health service all too often focuses narrowly on physical rehabilitation, a more holistic strategy for rebuilding lives and identities is called for. As one participant with arthritis who had recently recovered from a hip replacement argued:

There was never, and I think it was slightly disappointing, there's never ever been any lifestyle advice that I have ever been given, by consultants or rheumatologists, or anybody, which I think is quite disappointing. I think if you've got rheumatoid arthritis or any disease that makes you feel like death part of the time, or really hurting, or on a lot of tablets, you need some sort of 
advice you can have. ... when you've got arthritis you're not made aware enough that the lifestyle thing is as important as the pills.

Lifestyle choices and meaningful occupations may be as important to quality of life in illness as specific illness-management strategies. Further enquiry into disabled people's positive occupational strategies is recommended.

\section{Acknowledgements:}

With grateful thanks to the Arts \& Humanities Research Board, UK, for its financial support. This paper extends a presentation given to the Conference on Interpretative Phenomenological Analysis, at University College London, July 2002. 


\section{References:}

1. Lundmark, P. \& Bränholm, I. (1996) Relationship between occupation and life satisfaction in people with multiple sclerosis. Disability and Rehabilitation, 1996, 18: 449-53.

2. Reynolds, F. Coping with chronic illness and disability through creative needlecraft. British Journal of Occupational Therapy, 1997, 60: 352-56. 3. Ellis-Hill, C., Payne, S., Ward, C. Self-body split: issues of identity in physical recovery following a stroke. Disability and Rehabilitation, 2000, 22: 725-33.

4. Charmaz, K. Loss of self: a fundamental form of suffering in the chronically ill. Sociology of Health \& Illness, 1983, 5: 168-195.

5. Bury, M. Chronic illness as biographical disruption. Sociology of Health \& Illness, 1982, 4: 167-82.

6. Jackson, M. \& Quaal, C. Effects of multiple sclerosis on occupational and career patterns. Axon, 1991, 13: 16-22.

7. Sokka, T., Kautiainen, H., Mottonen, T., Hannonen, P . Work disability in rheumatoid arthritis 10 years after the diagnosis. Journal of Rheumatology, 1999, 26: $681-5$

8. Hakim, E., Bakheit, A., Bryant, T., Roberts, M., McIntosh-Michaelis, S., Spackman, A., Martin, J., McLellan, D. The social impact of multiple sclerosis: a study of 305 patients and their relatives. Disability and Rehabilitation, 2000, 22:288293.

9. Christiansen, C. Defining lives: occupation as identity - an essay on competence, coherence, and the creation of meaning. American Journal of Occupational Therapy, 1999, 53: 547-58. 
10. Finlayson, M., Impey, MW., Nicolle, C., Edwards, J. Self-care, productivity and leisure limitations of people with multiple sclerosis in Manitoba. Canadian Journal of Occupational Therapy, 1998, 65: 299-308.

11. Gulick, E. Correlates of quality of life among persons with multiple sclerosis. Nursing Research, 1997, 46: 305-311.

12. Zautra, A., Hamilton, N., Yocum, D. Patterns of positive social engagement among women with rheumatoid arthritis. Occupational Therapy Journal of Research, 2000, 20 (Suppl 1): 21S-40S.

13. Trainor, A. \& Ezer, H. Rebuilding life: the experience of living with AIDS after facing imminent death. Qualitative Health Research, 2000, 10: 646-660.

14. Monks, J. \& Frankenberg, R. Being ill and being me: self, body and time in multiple sclerosis narratives. In; Ingstad, B. \& Reynolds Whyte, S. (eds). Disability and Culture. Berkeley: University of California Press, 1995: 107-134.

15. Seymour, W. Remaking the body: rehabilitation and change. London: Routledge, 1998.

16. Kinney, W. \& Coyle, C. Predicting life satisfaction among adults with physical disabilities. Archives of Physical Medicine and Rehabilitation, 1992, 73: 863-869. 17. Wikström, I., Isacsson, Å., Jacobsson, T. Leisure activities in rheumatoid arthritis: change after disease onset and associated factors. British Journal of Occupational Therapy, 2001, 64: 87-92.

18. Drummond, A.E.R., \& Walker, M.F. A randomised controlled trial of leisure rehabilitation after stroke. Clinical Rehabilitation, 1995, 9: 283-290.

19. Taylor, L., McGruder, J. The meaning of sea kayaking for persons with spinal cord injuries. American Journal of Occupational Therapy, 1996, 50: 39-46. 
20. Hainsworth, J \& Barlow, J. Volunteers' experiences of becoming arthritis selfmanagement lay leaders: 'It's almost as if I've stopped aging and started to get younger!' Arthritis and Rheumatism, 2001, 45: 378-383.

21. Baer, B. The rehabilitative influences of creative experience. Journal of Creative Behaviour, 1985, 19 (3) 202-214.

22. Warren, B. Using the Creative Arts in Therapy: A Practical Introduction. 2nd Edition. London: Routledge, 1993.

23. Case, C. \& Dalley, T. (1992) The Handbook of Art Therapy. London: Routledge. 24. Malchiodi, C. Art therapy and medicine: powerful partners in healing. In; C. Malchiodi (ed). Medical art therapy with adults. London:Jessica Kingsley, 1999; $13-23$.

25. Schaverian, J. The revealing image: analytical art psychotherapy in theory and practice. London: Routledge, 1991.

26. Fisher, B \& Specht, D. Successful aging and creativity in later life. Journal of Aging Studies, 1999, 13: 457-72.

27. Zausner, T. When walls become doorways: creativity, chaos theory and physical illness. Creativity Research Journal, 1998, 11: 21-28.

28. Reynolds, F. Managing depression through needlecraft creative activities: a qualitative study. The Arts in Psychotherapy, 2000, 27: 107-114.

29. Gordon, P., Feldman, D., Crose, R. The meaning of disability: how women with chronic illness view their experiences. Journal of Rehabilitation, 1998, 64: 5-11. 30. Smith, J., Flowers, P., \& Osborn, M. Interpretative phenomenological analysis and the psychology of health and illness. In; Yardley, L. (ed). Material discourses of health and illness. London: Routledge, 1997; 68-91. 
31. Smith, J., Osborn, M., Jarman, M. Doing interpretative phenomenological analysis: In Murray, M. \& Chamberlain, K. (eds) Qualitative health psychology: theories and methods. London: Sage, 1999; 218-240.

32. Thompson, A., Kent, G \& Smith, J. Living with vitiligo: dealing with difference. British Journal of Health Psychology, 2002, 7: 213-225.

33. Caelli, K. The changing face of phenomenological research: traditional and American phenomenology in nursing. Qualitative Health Research, 2000, 10: 366377.

34. Kvale, S. InterViews: an introduction to qualitative research interviewing. London: Sage, 1996.

35. Quinn, A., Barton, J., Magilvy, J. Weathering the storm: metaphors and stories of living with multiple sclerosis. Rehabilitation Nursing Research, 1995, 4: 19-27.

36. Author. Symbolic aspects of coping with chronic illness through textile arts. Arts in Psychotherapy (in press)..

37. Csikszentmihalyi, M. Finding flow: the psychology of engagement with everyday life. New York: Basic Books, 1997.

38. Author. Stitching together past and present: narratives of biographical reconstruction during chronic illness. In: C. Horrocks, C., Milnes, K., Roberts, B., Robinson, D. (eds) Narrative, memory and life transitions. Huddersfield: University of Huddersfield Press. 2002; 127-136.

39. Charmaz, K. Good Days, Bad Days: the Self in Chronic Illness and Time. New Brunswick, NJ: Rutgers University Press, 1991.

40. Charmaz, K. From the 'sick role' to stories of self. In: Contrada, R. \& Ashmore, R. (eds) Self, social identity and physical health. Oxford: Oxford University Press, 1999; 209-239. 
41. Crossley, M . Introducing narrative psychology: self, trauma and the construction of meaning. Buckingham: Open University Press, 2000.

42. Do Rozario, L. Sprituality in the lives of people with disability and chronic illness: a creative paradigm of wholeness and reconstitution. Disability and Rehabilitation, 1997, 19: 427-434.

43. Moos R.H. \& Schaefer, J.A. The crisis of physical illness: an overview and conceptual approach. In; Moos, R.H. (ed.) Coping with Physical Illness, 2: New Perspectives. New York: Plenum Medical Book Co., 1984; 3-25.

44. Mohr, D., Dick, L., Russo, D., Pinn, J., Boudewyn, A., Likosky, W., Goodkin, D. The psychosocial impact of multiple sclerosis: exploring the patient's perspective. Health Psychology, 1999, 18: 376-382.

45. Robinson, I. Personal narratives, social careers and medical courses: analyzing life trajectories in autobiographies of people with multiple sclerosis. Social Science and Medicine, 1990, 30: 1173-1186.

46. Folkman, S. Positive psychological states and coping with severe stress. Social Science and Medicine, 1997, 45: 1207-1221.

47. Sanders, C., Donovan, J., \& Dieppe, P. The significance and consequences of having painful and disabled joints in older age: co-existing accounts of normal and disrupted biographies. Sociology of Health \& Illness, 2002, 24: 227-253. 
Table 1: Meanings of art for women living with chronic illness - key themes

\section{Coping with illness - focus on loss}

仓

- distracting thoughts from illness

- expressing grief

- filling an occupational void

- increasing choice and control - challenging victim status

- increasing mindfulness/awareness

- enabling the revising of priorities

- enabling flow and spontaneity

- facilitating humour, joy, positive emotions

- restoring a positive self-image

- building new social relationships

- contributing to others and making a difference

- widening horizons - new activities and future plans

I

\section{Living with illness - focus on gain}

